\title{
Relatos de Mulheres Submetidas à Biópsia do Linfonodo Sentinela quanto às Orientações Recebidas para Prevenção de Linfedema: um Estudo Qualitativo
}

Reports of Women who Underwent the Sentinel Lymph Node Biopsy as for Guidance Received for Preventing Lymphedema: a Qualitative Study Relatos de Mujeres Sometidas a la Biopsia del Linfonodo Centinela en Cuanto a las Orientaciones Recibidas para la Prevención de Linfógena: un Estudio Cualitativo

Caroline Kíssilla Pereira Pascoal' , Anke Bergmann², Maria Justina Padula Ribeiro ${ }^{3}$, Roberto José da Silva Vieira ${ }^{4}$, Helena Amaral da Fontoura ${ }^{5}$

\section{Resumo}

Este trabalho, produto de reflexôes decorrentes da dissertação de mestrado de uma das autoras, tem como objetivo mostrar a compreensão do conhecimento e da prática dos cuidados com o membro homolateral em mulheres submetidas à biópsia do linfonodo sentinela. $\mathrm{O}$ trabalho demonstra também que a atuação fisioterapêutica no pós-operatório de câncer de mama vai além dos aspectos físicos, abrangendo também questôes educativas. Essa abrangência minimiza as limitaçôes e mudanças nas atividades da vida das pacientes por meio da prática de orientações individualizadas e de acordo com suas características pessoais. Para tal, foram utilizadas dez entrevistas sobre as práticas de autocuidado com o braço do lado da cirurgia para prevençáo de linfedema em mulheres portadoras de câncer de mama e submetidas à técnica da biópsia do linfonodo sentinela. Este grupo específico de pacientes foi escolhido para verificar a ocorrência de alteraçôes nas atividades de suas vidas diárias. Ao final do trabalho, ressaltou-se a importância da existência de um manual com orientaçóes sobre a biópsia do linfonodo sentinela. O manual deve ser elaborado e utilizado multidisciplinarmente, determinando as informaçôes mais relevantes sobre cada área de atuação profissional, especialmente em relação às práticas de autocuidado pertinentes à prevençáo de linfedema.

Palavras-chave: Biópsia de Linfonodo Sentinela; Linfedema; Neoplasias da Mama; Autocuidado; Análise Qualitativa

Trabalho realizado no Hospital do Câncer III (HC III) do Instituto Nacional de Câncer (INCA).

${ }^{1}$ Mestre em Ciências da Saúde. Fisioterapeuta. Centro de Oncologia e Radioisótopos. Mestranda do Instituto Fernandes Figueira (IFF/FIOCRUZ) e bolsista do CNPq no momento da realização da pesquisa.

${ }^{2}$ Doutora em Saúde Pública. Coordenação de Educação do INCA.

${ }^{3}$ Serviço de Fisioterapia do HC III/INCA.

${ }^{4}$ Médico da Fundação Oswaldo Cruz. Doutor em Saúde da Criança e da Mulher/IFF/FIOCRUZ.

${ }^{5}$ Doutora em Saúde Pública. Professora adjunta da Universidade Estadual do Rio de Janeiro.

Endereço para correspondência: Caroline Kíssilla Pereira Pascoal. Rua Dezenove de Abril, 310 - Bairro das Águas - Ipatinga (MG), Brasil. CEP: 35160-160.

E-mail: carolkissilla@yahoo.com.br 


\section{INTRODUÇÃO}

Este trabalho, produto de reflexôes decorrentes da dissertação de mestrado de uma das autoras, tem como objetivo mostrar a compreensão do conhecimento e da prática dos cuidados com o membro homolateral em mulheres submetidas à biópsia do linfonodo sentinela (BLS), demonstrando também que a atuação fisioterapêutica no pós-operatório de câncer de mama vai além dos aspectos físicos e abrange questóes educativas, minimizando as limitaçôes e mudanças nas atividades da vida das pacientes, através da prática de orientaçôes individualizadas e de acordo com as características de cada uma. Para tal, trabalharam-se relatos de entrevistas sobre as práticas de autocuidado com o braço do lado da cirurgia para prevenção de linfedema em mulheres portadoras de câncer de mama e submetidas à técnica da BLS e verificou-se se ocorrem ou não alteraçóes nas atividades da vida diária das mesmas.

A palavra câncer tem origem do grego karkinos (para as úlceras neoplásicas não cicatrizantes) e karkinôma (para tumores malignos sólidos) e; no latim, cancer, que significa caranguejo, designado à doença pela semelhança existente entre as veias intumescidas ao redor do tumor e as patas do caranguejo. Nessa perspectiva, o câncer está associado à sensação consciente ou inconsciente de ser devorado, ser comido por dentro, reforçando a dimensão de doença incurável, castigo, entre outros significados ${ }^{1}$.

O fato de ter câncer, uma doença repleta de estigmas, altera a percepção da mulher sobre si mesma ${ }^{2}$. As reaçóes das pacientes frente à doença, ao tratamento e à reabilitação, segundo Venâncio, dependem de características individuais, tais como: história de vida, contexto social e cultural, espiritualidade e opção sexual ${ }^{3}$.

Segundo estimativa do Instituto Nacional de Câncer (INCA $)^{4}$, o câncer de mama é o segundo tipo de câncer mais frequente no mundo e o mais comum entre mulheres. A intervençáo cirúrgica tem sido usada há muitos anos como principal opção terapêutica, com objetivos de promover o controle local através da remoção mecânica das células malignas presentes no câncer primário, proporcionar maior sobrevida, orientar a terapêutica sistêmica, definir o estadiamento cirúrgico da doença e identificar o risco de metástases. $\mathrm{O}$ esvaziamento axilar, por sua vez, é realizado com a finalidade de determinar o estadiamento cirúrgico da doença na axila, avaliar o prognóstico no que se refere à recidiva local e à distância e orientar a terapêutica complementar. A necessidade da linfadenectomia total é questionada, uma vez que grande parte das mulheres náo possui linfonodos axilares acometidos pela doença e este procedimento favorece a instalaçáo do linfedema, uma vez que compromete a produção de células de defesa e drenagem linfática do membro ${ }^{4,5,6,7}$.

Conceitua-se linfedema como todo e qualquer acúmulo de líquido, altamente proteico nos espaços intersticiais, seja por falhas de transporte devido a alteraçóes de carga linfática ou por falha da proteólise extra linfática ${ }^{8}$. Essa morbidade causa alterações importantes, não só físicas, mas também funcionais e estéticas, por alterar a imagem corporal. Para prevenção do linfedema, procedimentos que vêm acompanhados do risco de lesão devem ser evitados. Assim sendo, retirar cutícula com alicate, lavar louças, praticar jardinagem, aferir pressão arterial, manipular equipamentos cortantes ou quentes, costurar, usar lâmina cortante para retirada de pelos axilares, dentre outros, são atividades a serem evitadas ou realizadas com equipamento de proteçáo (luvas), no braço do lado da mama operada; além da cinesioterapia orientada, o posicionamento do membro, a realização de automassagem e a hidratação do braço devem ser estimulados, ${ }^{9,6,10,7,11}$.

$\mathrm{Na}$ tentativa de minimizar as morbidades causadas pela linfadenectomia axilar (LA), alguns estudiosos se empenharam no desenvolvimento da técnica da biópsia do linfonodo sentinela (BLS) para tratamento do câncer de mama. Essa técnica emergiu na década de 1990 como um método de amostragem axilar seletiva, minimamente invasiva e altamente sensível na identificação de metástases, permitindo estudo anatomopatológico completo dos linfonodos que têm maior probabilidade de apresentarem metástases. Segundo Veronesi et al., a biópsia do linfonodo sentinela foi desenvolvida com o objetivo de possibilitar qualidade de vida com menor morbidade, sendo uma alternativa oncologicamente válida e melhor tolerada pelas pacientes do que a linfadenectomia radical ${ }^{12,13}$.

Embora sejam inúmeras as vantagens da técnica da biópsia do linfonodo sentinela, em nosso país, a maioria das pacientes chega às instituiçóes que realizam o tratamento cirúrgico do câncer de mama com estadiamento avançado da doença, sendo, em geral, a mastectomia a cirurgia de escolha, associada à abordagem axilar mais complexa que $\mathrm{BL} \mathrm{S}^{14}$.

Em face do imaginário social, a abordagem do câncer envolve sentimentos que são difíceis de serem administrados, tanto por parte dos profissionais como por parte das pessoas em geral. $\mathrm{O}$ medo da dor, a resignação diante da percepção de que sua doença terá um desfecho fatal e a negação de que a própria doença existe são alguns dos aspectos emocionais que envolvem toda a trajetória de ser portador de câncer ${ }^{15}$.

O fisioterapeuta, como profissional atuante nesse campo, que reabilita e orienta as mulheres com câncer de mama, para assistir a sua clientela de forma integral, precisa compreender as interpretaçóes e os significados dados a cirurgia axilar e as práticas de autocuidado com o braço homolateral a esse procedimento para prevençáo do linfedema. Através dessa compreensão, é possível direcionar os atendimentos para as singularidades das mulheres, possibilitando a adequada utilização das informações e orientaçôes fornecidas, sem causar limitação ou restriçấo nas atividades da vida diária de cada uma, levando a uma melhora na qualidade de vida dessas pacientes.

No Hospital do Câncer III (HC III/INCA), mulheres submetidas à técnica da BLS recebem as mesmas 
orientaçôes que as submetidas à LA; o grupo da BLS, porém, tem menor risco de desenvolver linfedema e é orientado quanto a esse fato.

$\mathrm{O}$ questionamento que direcionou essa investigaçáo caminhou na linha de investigar os conhecimentos e práticas das orientaçóes recebidas para prevenção do linfedema no grupo de mulheres submetido à BLS, levando em consideração o conhecimento dessas mulheres sobre a menor chance de desenvolverem linfedema. Será que essas mulheres seguem as orientaçóes de autocuidado com o braço? Será que elas mudam suas atividades de vida diária? Será que esse grupo de mulheres compreende as informaçôes fornecidas?

O autocuidado é usado como sinônimo de cuidado de si próprio. É um comportamento que implica no papel ativo do cliente, em prática de atividades que o indivíduo desempenha em seu próprio benefício, a fim de manter a vida, a saúde e o bem-estar ${ }^{16}$.

A comunicação, compreendida como processo de compartilhamento de informaçóes fornecidas e recebidas, possibilita alteraçóes no comportamento das pessoas envolvidas em curto, médio e longo prazo. Todo processo de comunicação é constituído por troca e partilha de informaçôes. Portanto, para que esse processo seja completo, é necessário que as partes estejam informadas, prontas para tomarem atitudes com pleno conhecimento das ideias e sentimentos comuns ${ }^{17}$.

É a partir dos relatos sobre conhecimentos e práticas de autocuidado das mulheres submetidas à BLS que se buscam as respostas para os questionamentos que motivaram a realização desta pesquisa.

Acredita-se que, através da análise das entrevistas e do diálogo com a literatura científica utilizada neste estudo, se contribuirá para que a assistência fisioterapêutica no pósoperatório tenha, além da funçấo reabilitadora e educativa, a capacidade de minimizar as limitaçóes e mudanças nas atividades da vida das pacientes, através da prática de orientaçóes individualizadas e de acordo com as características de cada uma. Portanto, este estudo visou à compreensão do conhecimento e da prática dos cuidados com o membro homolateral em mulheres submetidas à BLS.

\section{METODOLOGIA}

Este estudo foi realizado no HC III/INCA, na cidade do Rio de Janeiro, em uma abordagem qualitativa na busca de entender o significado que os sujeitos atribuem às situações vividas e a relação desses significados com a realidade na qual estáo inseridos ${ }^{18}$.

Foram realizadas dez entrevistas semiestruturadas com mulheres que chegavam ao setor para reavaliação fisioterapêutica, no período de agosto a outubro de 2007. Como critério de inclusão, determinou-se que as participantes devessem ter entre 6 e 18 meses de cirurgia realizada com a técnica da BLS e idade entre 40 e 60 anos. Os critérios de inclusão e exclusão foram determinados visando à maior homogeneidade do grupo. A todas as participantes foi solicitado que lessem e assinassem um Termo de Consentimento Livre e Esclarecido, conforme a Resolução 196/96 do Conselho Nacional de Saúde ${ }^{19}$. A pesquisa de número 051/07 foi aprovada pelo Comitê de Ética e Pesquisa do INCA.

Foram encontradas nove mulheres submetidas à técnica da BLS que não realizaram LA (linfonodo sentinela negativo) e uma submetida a esvaziamento axilar em um segundo tempo cirúrgico (linfonodo sentinela positivo). Outras três mulheres participantes foram submetidas à mastectomia simples com reconstrução imediata; das quais, uma teve infecção no pós-operatório, sendo necessária a retirada da prótese de silicone utilizada na reconstrução. A idade das participantes variou entre 40 e 59 anos. Participaram da pesquisa mulheres casadas, viúvas e divorciadas.

Foram realizadas entrevistas semiestruturadas visando a alcançar os objetivos propostos. Tais entrevistas possibilitaram às entrevistadas compartilhar opiniōes e expressar sentimentos, percepçôes, conhecimentos e significados a respeito do tema. Para conduzir as entrevistas, foi elaborado um roteiro de perguntas com tópicos sobre a vida da mulher: antes da cirurgia; sobre a cirurgia; e o "significado" do procedimento cirúrgico na vida da paciente.

Para organizaçáo e análise dos dados, utilizou-se a técnica de Análise de Conteúdo, trabalhando a palavra e as significaçóes das mensagens, buscando a lógica do material coletado, através de três etapas: pré-análise; análise do conteúdo e tratamento; e interpretação dos resultados ${ }^{18}$.

Da análise dos dados, emergiram categorias temáticas que abrangem as questóes abordadas nas entrevistas mudanças nas atividades da vida, informaçóes sobre a técnica cirúrgica e práticas de autocuidado para prevenção de linfedema e importância do procedimento cirúrgico na vida da mulher.

\section{RESULTADOS E DISCUSSÃO}

As mudanças de vida e as limitaçóes ocorreram de diferentes maneiras entre as entrevistadas, de acordo com as interpretaçôes que faziam das informaçóes recebidas e dos significados construídos sobre o linfedema ao longo de suas vidas.

As afirmaçôes de Bergamasco \& Ângelo e Tavares \& Tyad confirmam-se através da análise dos depoimentos, ao se perceber que algumas mulheres, após aprender ou reconhecer a possibilidade de alterar suas atividades da vida diária, quando deparam com o diagnóstico do câncer de mama, integram seu novo ser de forma produtiva e saudável, alterando a percepçáo sobre elas mesmas. Isso pode ser visto no depoimento transcrito abaixo ${ }^{2,19,20}$.

Não estou trabalhando. Estou afastada pelo INSS. Então estou aproveitando o tempo para estudar, que era um sonho muito antigo meu (M.B.). 
$\mathrm{O}$ relato de MB ilustra a ideia de Bondia sobre a experiência ser uma abertura para o desconhecido e não uma meta que se conhece de antemáo. Ela faz da experiência do diagnóstico do câncer uma abertura para os estudos que, até o momento, eram para ela desconhecidos como possibilidade ${ }^{21}$.

Nesse mesmo relato, fica explícita a realização do autocuidado por essa mulher; segundo conceito de Orem, as mulheres desempenham papel ativo em seu próprio benefício, a fim de manter a vida, a saúde e o bem-estar ${ }^{16}$.

Algumas das orientaçôes fornecidas pelos profissionais de saúde para a prevençâo do linfedema estâo diretamente relacionadas às atividades do cotidiano das participantes. Adaptar essas tarefas às novas condiçóes da mulher após a cirurgia, pedir auxílio para realizá-las ou simplesmente não realizá-las são alternativas encontradas pelas entrevistadas, de acordo com os relatos analisados como, por exemplo, o que segue abaixo:

[...] eu não consigo estender uma roupa na corda, subo em uma cadeira para poder estender e outras coisas assim [...] estou fazendo vista grossa para muitas coisas [...]. [...] deixo a casa suja, roupa sem passar. Eu antes não deixava roupa sem passar, agora eu finjo que não vejo. É uma necessidade [...] (R.C.).

Essa ajuda, solicitada a outras pessoas, pode ser interpretada como um sentimento de impotência por algumas entrevistadas e como um evento natural e necessário por outras, de acordo com as características individuais e contextuais que cada mulher vivencia ${ }^{3}$.

O sentimento de impotência pode ser explicado, como sugerem Vieira \& Queiróz, pelo fato de a mulher assumir o papel de doente após o diagnóstico do câncer, além de todos já desempenhados anteriormente.

Bervian \& Perli, após entrevistarem familiares de mulheres submetidas à cirurgia para câncer de mama, escreveram que os entrevistados relataram aspectos que os fizeram mudar de comportamento e passar a auxiliar as mulheres em diversas atividades, como forma de proporcionar bem-estar e tranquilidade à máe-esposa. Os mesmos autores encontraram em seu grupo de estudo que, após o adoecimento, a família mudou, tornando-se mais unida. Os trechos que seguem abaixo corroboram esses autores, pois nos indicam que o senso de colaboração é desenvolvido entre os membros da família ou pessoas próximas ${ }^{22,23}$.

Se eu vou ao supermercado, eles ficam: mãe, deixa que eu levo o carrinho! E essas coisas assim [...]. Isso tem um lado ruim, porque a gente se sente diferente, dependente (R.C.).

Quando eu vou trabalhar sempre levo alguém comigo. Sempre levo algum residente, uma colega, porque às vezes tem que entubar um paciente que exige um pouco mais de força. Eu passo a peteca! (E.R.).
O constrangimento de ser acometida por uma doença cheia de estigmas levou algumas participantes do estudo realizado por Almeida et al. a se afastarem das pessoas de seu convívio social, assim como no presente estudo. Makluf et al. escreveram que o sentimento de pena transparece no olhar de quem vê um paciente com câncer ${ }^{24,25}$.

Às vezes eu deixo de ir a determinados lugares porque as pessoas ficam me perguntando as coisas. Muita gente sabe da minha cirurgia e muita gente fica perguntando. Têm pessoas indiscretas que querem até ver! (R.C.).

$\mathrm{O}$ isolamento social e o medo de as pessoas verem o corpo alterado, descritos por Almeida et al. e por Maklu et al., foram relatados pela entrevistada submetida à mastectomia simples com reconstrução, confirmando que o estigma acerca da doença tem uma representação significativa, indo além do fato de não ter a mama. $\mathrm{O}$ processo de ser questionado e examinado por pessoas do convívio social demonstra o desconhecimento sobre a doença, consagrando a existência dos estigmas da dor, morte e sofrimento.

O medo do diagnóstico do câncer, da recorrência ou de progressão da doença foi referido pelas entrevistadas de sua pesquisa, tanto para estágio precoce da doença quanto para o avançado ${ }^{26}$. Em outro estudo, o medo emergiu quando as mulheres procuraram compreender o processo de adoecimento e tentaram dar significado a ele.

Neste trabalho, essa expressão sugeriu diferentes sentidos. Relataram medo de surgimento de linfedema, de recidiva da doença, de o braço inchar. Tal apreensão pode estar associada a conhecimentos e experiências na vida das pacientes, prévias à doença ${ }^{24}$.

Com relação ao linfedema, os achados deste trabalho corroboram a afirmação de Gomes et al. sobre a associação do medo do linfedema ao aspecto físico, dano funcional e sérias consequências mentais; além de ser foco de atenção das pessoas, podendo estar associado a experiências negativas anteriores ou a conceitos que são compartilhados cultural e socialmente, o que nos leva a refletir sobre a possibilidade de esse medo ser consequente à não realização das práticas de autocuidado.

A gente pega medo de tudo! Ai, será que meu braço vai inchar? Será que se eu dormir em cima do meu braço vai inchar? Você pega medo de tudo! (M.E.).

[...] tenho mesmo (medo do linfedema), porque acho que isso é uma referência, porque você vê as pessoas assim, você já sabe o que as pessoas têm né? (R.C.).

Na segunda categoria de análise - conhecimentos sobre a cirurgia e autocuidado com o membro homolateral à BLS -, constatou-se uma homogeneidade nas respostas relacionadas aos conhecimentos dos cuidados necessários 
com o braço para prevenção do linfedema. Quando questionadas a esse respeito, as pacientes davam respostas positivas e citavam algumas das orientaçóes de que se lembravam. Dentre essas citaçóes, a retirada da cutícula foi mencionada por grande parte das participantes. A prática do autocuidado, relacionada a esse procedimento deu lugar a outro tipo de cuidado consigo mesma: a vaidade em manter as unhas bonitas. As entrevistadas não demonstram nenhum cuidado frente a esse procedimento; e, para esse grupo, as práticas de autocuidado não parecem estar acontecendo para prevenção do linfedema. Não se pode, porém, deixar de valorizar o conceito de autocuidado com o qual se está trabalhando - cuidar de si próprio. Assim sendo, pode-se dizer que as entrevistadas estão praticando autocuidado, porém não estão visando à prevenção do linfedema.

Olha, isso, vou dizer a você, eu faço mesmo! (retirar cutícula da mão). Eu sou muito vaidosa! Não consigo! (E.R.).

No pós-operatório, pacientes submetidas à LA e à mastectomia simples com BLS participam de uma palestra organizada por profissionais da enfermagem. Neste momento, recebem um manual de orientaçôes sobre cuidados com o dreno, o curativo e o membro homolateral à cirurgia. As mulheres operadas apenas com BLS recebem, no leito, algumas informaçôes desses profissionais, porém não recebem o manual da enfermagem e não são informadas quanto à prática do autocuidado nas tarefas realizadas com o braço, visando à prevenção de linfedema, como o grupo de LA.

No momento da realização do pós-operatório - a cargo da equipe de fisioterapia -, as pacientes que realizaram LA recebem, em grupo, orientaçóes quanto à possibilidade de se realizar a cinesioterapia, posicionamento do braço e práticas de autocuidado, visando à prevenção do linfedema, além de orientaçôes voltadas para a prática das atividades cotidianas. Essas orientaçôes são fornecidas verbalmente e através de uma cartilha. Esses mesmos recursos são utilizados para orientar as pacientes de BLS; porém, para esse grupo, as orientaçōes são oferecidas individualmente e as pacientes são alertadas para a menor chance que possuem de desenvolver o linfedema.

As informaçóes acima citadas são reforçadas pelo fisioterapeuta, 30 dias após a cirurgia, quando a paciente comparece ao setor para reavaliação fisioterapêutica, seguindo a rotina do Serviço.

Mesmo frente a todas essas orientaçóes, se percebeu que nem todas as pacientes compreendem e seguem as práticas de autocuidado, motivo este que nos levou a questionar sobre a necessidade de as informaçóes serem mais próximas e únicas, direcionadas a cada mulher e transmitidas após um consenso entre os próprios profissionais de saúde, para que alcancem seus objetivos esclarecedores e não causem dúvidas.
As informaçóes, geralmente, são fornecidas de maneira semelhante a todas as pacientes, independente do nível escolar, cultural, idade, profissão e do tipo de cirurgia proposta. Além do mais, são fornecidas sem um consenso entre os profissionais e em um momento que, para muitas mulheres, é repleto de expectativas, medo, insegurança, conflitos, o que pode prejudicar a compreensão das mesmas.

Embora tenha consciência da importância de seguir os cuidados com o braço, uma entrevistada descreve sua realidade. Por não ter quem execute as tarefas em seu lugar, é indispensável que ela própria realize determinadas atividades, mesmo frente ao risco que trazem para o surgimento do linfedema.

[...] na vida real mesmo, têm certas coisas que eu não faço. Não tenho empregada. Eu tenho que fazer as coisas, tenho que passar a roupa [...] (A.M.).

Levando em consideração o conceito de prevenção, percebeu-se a necessidade de se adaptar as informaçóes de acordo com as singularidades de cada mulher ${ }^{22}$.

Reforçar-se, aqui, com base em nossos achados e nas afirmaçôes de Bergamasco \& Ângelo, a importância de os profissionais de saúde irem ao encontro das necessidades informativas e educativas das mulheres, para facilitar no enfrentamento da doença e restaurar um senso de normalidade e independência física.

Cientes de que as informaçóes sobre o procedimento cirúrgico são fornecidas a todas as pacientes, alguns relatos chamam a atenção quando as mulheres dizem não terem sido informadas, o que nos leva a inferir três possibilidades: a orientação não está sendo transmitida de maneira compreensiva, levando em consideração as singularidades existentes em cada ser, ou o momento não está sendo oportuno para a recepção, compreensão e assimilação das informaçôes, ou ainda a divergência na transmissão dessas informaçóes está sendo causa de dúvidas na vida das pacientes.

Ih! sabe que nem me informei disto? - Informaçóes sobre a cirurgia (M.S.).

Não, não sei e não me explicaram isso (N.S.).

Não se pode deixar de considerar que a falta de informação e de suporte profissional podem contribuir enormemente para essa divergência nas informaçóes ${ }^{25}$. Na luta pela vida, encontrou-se, entre as entrevistadas deste estudo, uma participante que explicitou o desejo de retirada da mama, mesmo frente à possibilidade de uma cirurgia conservadora. Tal relato deixa subentendido o desejo da entrevistada de, junto à mama, serem eliminadas todas as questóes relacionadas ao câncer, não havendo mais necessidade de se preocupar com a doença. Achado semelhante foi relatado por Vieira et al. e por Bergamasco \& Ângelo.

A participação da paciente na opção pelo tratamento pode funcionar como ajuda na elaboração do problema 
e possibilitar o fortalecimento interno necessário para o enfrentamento da doença $a^{23}$.

O médico me disse que tínhamos dois tipos de cirurgia. Uma para retirar o quadrante e outra para retirar toda a mama. - Eu disse: Doutor, o que tem que ser feito? - Ele disse: não é o que tem que ser feito, é o que a senhora quer fazer [...]. - Eu disse: doutor tira logo tudo! (M.T.).

Analisando a terceira categoria - significado/ importância do procedimento na vida da mulher -, viuse que, embora nem todas as entrevistadas soubessem informar sobre o procedimento cirúrgico realizado, elas sabiam que, possuindo os linfonodos axilares preservados, a chance de desenvolver o linfedema seria menor.

Foi importante sim. [...] porque pelo que eles falaram, foi menos risco do braço inchar (N.S.).

O linfedema foi interpretado como uma 'referência' de quem teve câncer, um sinal visível e representativo da doença. Este fato está de acordo com a afirmação de ser essa morbidade a causa de restriçóes na vida da mulher e, ainda, uma das razóes que leva ao impacto negativo na qualidade de vida, em virtude do isolamento social que pode ocorrer ${ }^{15}$.

[...] tenho mesmo (medo do linfedema), porque acho que isso é uma referência. Porque você vê as pessoas assim e você já sabe o que as pessoas têm, né? (R.C.).

Embora o linfedema tenha um impacto negativo na qualidade de vida das mulheres acometidas, foi encontrada, entre as entrevistadas, uma participante submetida à BLS negativa, com linfedema controlado, que não relatou incômodo em possuir tal morbidade.

Ele não me incomoda. Não procuro saber porque inchou (M.T.).

A frase acima pode demonstrar a insegurança da paciente frente ao medo do que pode estar associado ao referido problema. Pode, também, estar relacionada à real indiferença da paciente perante o linfedema; ou, ainda, demonstrar seu desconhecimento quanto às consequências futuras do quadro iniciado. Ao mesmo tempo, o fato de a entrevistada dizer que não procura saber por que o braço inchou parece nos transmitir insegurança em admitir a falta da prática do cuidado com si mesma.

As pacientes com linfonodos axilares preservados, no grupo estudado, sabem da relação do linfonodo sentinela com a menor chance de desenvolver linfedema e se aproveitam desse benefício para justificarem a não realização de práticas de autocuidado que possam levar ao aparecimento desse edema no braço. Entre as falas relacionadas a esse aspecto, percebeu-se mais uma vez a preocupaçáo das entrevistadas com questóes relacionadas ao feminino, como a cutícula das unhas e a estética prejudicada por um linfedema em membro superior. Beneficiam-se do procedimento cirúrgico a que foram submetidas para dar continuidade a atividades que reforçam a feminilidade.

Pelo que eu percebi né, tendo esses linfonodos preservados, minha segurança é maior, tenho minha proteção. [...] até minha unha, que eu gosto de manter feitinha, essas coisas assim que fazem parte do dia a dia da gente e mais essa preocupação de não ter o braço inchado, que é uma coisa que esteticamente é muito feio [...] (R.C).

Aí eu ia ter consciência que se eu tivesse feito o esvaziamento, eu não ia poder tirar cutícula (A.M.).

As entrevistadas submetidas à BLS negativa, mesmo frente à preservação da mama, relataram limitaçôes, inseguranças e mudanças nas atividades da vida, o que podem estar relacionadas às divergências das informaçōes fornecidas pelos profissionais.

Notou-se, no grupo de entrevistadas, que houve mudança nas atividades da vida das mulheres. $\mathrm{O}$ que não ficou claro, entretanto, foi se essas ocorreram em virtude das orientaçóes recebidas para as práticas de autocuidado ou consequentes ao fato de ter câncer, uma doença cheia de estigmas. As pacientes deixam de realizar algumas atividades para prevenir o linfedema e acabam por adquirir outras complicaçôes, como isolamento social, depressão, sentimentos de desvalorização social, dependência funcional, entre outros.

Embora nem todas as participantes tenham demonstrado conhecimento sobre a técnica cirúrgica realizada, elas foram unânimes com relaçáo ao conhecimento do benefício da BLS, na menor incidência do linfedema. Ficou evidente com a leitura dos relatos o quanto o linfedema é temido e encarado como um marco do câncer de mama. É importante que as pacientes entendam a relevância das orientaçôes e realizem suas atividades com consciência de que não estão impedidas de cuidarem de si e de outras pessoas, sendo possível uma vida normal. Para tanto, é necessário que os profissionais de saúde orientem seus pacientes de acordo com suas atividades diárias (profissão, vida social, lazer) e que o fisioterapeuta seja um reabilitador dentro de seu amplo universo de atuação, indo além do 'corpo humano', atingindo o 'ser humano'.

$\mathrm{Na}$ busca de literatura sobre o tema, notou-se que o enfoque multidisciplinar é dado ao grupo de pacientes submetidas à $\mathrm{LA}$, porém, quando relacionadas à BLS, os artigos encontrados são voltados para a quantificação e caracterização das morbidades, e não para relatos únicos de conhecimentos e práticas, de acordo com a vivência das mulheres. 


\section{CONCLUSÕES}

Em conclusão, por meio dos relatos analisados em nossa pesquisa, constatou-se que a comunicação entre profissionais de saúde e pacientes não vem acontecendo de maneira eficaz, e sim normativa e generalizadamente. Torna-se necessária uma melhora desse processo, através da elaboração de um consenso entre os profissionais para que as orientaçóes sejam transmitidas de maneira clara, objetiva e coerente, pois se tem que levar em consideraçáo que a compreensão da paciente frente ao que escutou é consequência de uma série de mudanças e limitaçóes tanto na vida pessoal quanto profissional, social e familiar.

Ressalta-se a importância da existência de um manual com as orientaçôes sobre a BLS, elaborado e utilizado multidisciplinarmente, determinando as informaçóes mais relevantes sobre cada área de atuação profissional, especialmente em relação às práticas de autocuidado pertinentes à prevenção de linfedema, já que essa é a preocupação deste trabalho. Pode-se inferir que um manual assim programado sirva como um guia norteador das questóes a serem esclarecidas, cabendo ao profissional de saúde transmitir essas informaçóes de acordo com cada indivíduo, respeitando sua inserção no contexto sócio-histórico-cultural. Acredita-se que, dessa maneira, os objetivos das informaçóes poderão ser alcançados e as pacientes poderão ter uma vida com menos limitaçóes, preocupações e medos.

Concluiu-se, ainda, que a fisioterapia, cumprindo seu papel de envolver a paciente no autocuidado, interagindo com o outro em sua totalidade, de acordo com suas singularidades e, náo apenas fornecendo orientaçóes sobre sua patologia e seu tratamento, é capaz de tornar compreensível a necessidade dos cuidados, sem tantas limitaçóes nas atividades da vida diária de cada mulher. Os fisioterapeutas, assim como outros profissionais de saúde, têm obrigação ética e profissional de se prepararem para atender a esse público de maneira eficiente, o que possibilitará a prevenção do linfedema e contribuirá para a melhora da qualidade de vida das pacientes acometidas de câncer de mama.

\section{AGRADECIMENTOS}

A todas as pacientes que participaram desta pesquisa $\mathrm{e}$ à equipe do Serviço de Fisioterapia do HC III/INCA.

\section{Declaraçáo de Conflito de Interesses: Nada a Declarar REFERÊNCIAS}

1. Braz MM. Aprendendo com o câncer de mama: emoções e percepções de pacientes e profissionais de fisioterapia, 2001. [dissertação]. Universidade Federal de Santa Catarina: Florianópolis, 2001. 110p.

2. Tavares JSC, Tyad LAB. Metáforas e significados do câncer de mama na perspectiva de cinco famílias afetadas. Cad Saude Publica 2005; 21(2): 426-35.
3. Venâncio JL. Importância do psicólogo no tratamento de mulheres com câncer de mama. Revista brasileira de cancerologia 2004; 50 (1): 55-63.

4. Instituto Nacional de Câncer (Brasil). Estimativa 2010: incidência de câncer no Brasil. Rio de Janeiro: INCA; 2009.

5. Paz AV et al. Biópsia de linfonodo sentinela; experiência clínica. Revista brasileira de cancerologia 2001; 47 (3):309-15.

6. Camargo MC, Marx AC. Reabilitação física no câncer de mama. São Paulo: Editora Rocal; 2000.

7. Magaldi CM et al. Avaliação da morbidade e funcionalidade do membro superior em mulheres submetidas à linfadenectomia axilar total e biópsia de linfonodo sentinela por câncer de mama. Revista brasileira de mastologia 2005; 1:9-14.

8. Mayall R. Linfangiopatias e hitopatologia. In: Linfangites e erisipelas. 2.ed. Rio de Janeiro: Revinter; 2000.

9. Cantinelli FS, Camacho RS, Smaletez O, Gonsales BK, Braguittoni E, Rennó JJ. A oncopsiquiatria no câncer de mama - considerações a respeito de questóes do feminino. Revista de psiquiatria clínica 2006; 33 (3):124-33.

10. Gozzo TO. Movimentação precoce do braço no controle do seroma pós-linfadenectomia axilar. 2005. [dissertação]. Ribeirão Preto (SP): Universidade de São Paulo; 2005.

11. Panobianco MS, Mamede MV. Complicações e intercorrências associadas ao edema de braço nos três primeiros meses pós mastectomia. Rev Lat Am Enfermagem 2002; 10(4):544-51.

12. Harris JR et al. Doenças da mama. 2.ed. Rio de Janeiro: Editora Medsi; 2002.

13. Veronesi U, Paganelli G, Viale G et al. A randomized comparizon of sentinel-node biopsy with routine axillary dissection in breast cancer. N Engl J Med 2003; 349(6):546-53.

14. Sales CA et al. Qualidade de vida em mulheres tratadas de câncer de mama: funcionamento social. Revista brasileira de cancerologia 2001; 47(3):263-72.

15. Gomes R, Skaba. MMVF, Vieira RJS. Reinventando a vida: proposta para uma abordagem sócio-antropológica do câncer de mama feminina. Cad Saude Publica 2002; 18 (1).

16. Orem DE. Acta paulista de enfermagem 1997; 7 (1): 19-26.

17. Silva MJP. O papel da comunicação na humanização da atenção ä saúde. Revista Bioética 2002; 10(2):123-27.

18. Minayo MSC. O desafio do conhecimento: pesquisa qualitativa em saúde. São Paulo: Hucitec, 2004.

19. Decreto-Lei n. 938, de 13 de outubro de 1969. Diário Oficial da União. (Out. 1969).

20. Bergamasco RB, Ângelo MO. O sofrimento de descobrir-se com câncer de mama: como o diagnóstico é experienciado pela mulher. Revista brasileira de cancerologia 2001; 47(3): 277-82. 
21. Bondia LJ. Notas sobre a experiência e o saber da experiência. Revista brasileira de educação2002.

22. Vieira PC, Queiroz MS. Representações sociais sobre câncer feminino: vivência e atuação profissional. Psicologia social 2006; 18 (1).

23. Bervian, PI, Perli NMOG. A família (com) vivendo com a mulher/mãe após a mastectomia. Revista brasileira de cancerologia 2006; 52(2):121-28.
24. Almeida AM, Mamede MM, Panobianco MS. Construindo o significado da recorrência da doença: a experiência de mulheres com câncer de mama. Rev Lat Am Enfermagem 2001; 9 (5): 63-39.

25. Makluf ASD, Dias RC, Barra AA. Avaliação da qualidade de vida em mulheres com câncer de mama. Revista brasileira de cancerologia 2006; 52(1): 49-58.

\section{Abstract}

This study, a product of the reflections from a master dissertation by one of the authors, aims to show the comprehension of knowledge and practices in the assistance of the ipsilateral limb in women who have undergone sentinel node biopsy. It also demonstrates that physiotherapeutic assistance on breast cancer surgery postoperative period goes beyond physical aspects, comprehending educational issues as well. This comprehension minimizes limitations and changes on their daily activities through practices of individualized guidance and in accordance with their own characteristics. For this purpose, ten interviews were used and they focused the self-care practices with the arm of the same side of the surgery to prevent lymph edema in women who had breast cancer and underwent the technique of the lymph node sentinel biopsy. This particular group of patients was chosen to observe whether alterations in their daily activities were related to the technique. At the end of the paper the importance of a manual containing guidance on the sentinel lymph node biopsy was highlighted. This manual should be designed and used in a multidisciplinary way, stating the most relevant information on each area of professional performance, especially concerning the practices of self-care pertinent to preventing lymph edema.

Key words: Sentinel Lymph Node Biopsy; Lymphedema; Breast Neoplasms; Self Care; Qualitative Analysis

\section{Resumen}

Este trabajo, como producto de reflexiones decurrentes de la disertación de maestría de una de las autoras, tiene el objetivo de mostrar la comprensión del conocimiento y de la práctica de los cuidados con el miembro homolateral en mujeres sometidas a la biopsia del linfonodo centinela. Ese estudio también demuestra que el desempeńo fisioterapéutico en el postoperatorio del cáncer de mama va allá de los aspectos físicos y abarca cuestiones educativas, lo que minimiza las limitaciones y cambios en las actividades de la vida de los pacientes, por medio de la práctica de orientaciones individuales y según las características de cada una. Para tal, se utilizaron diez entrevistas acerca de las prácticas del autocuidado con el brazo del mismo lado de la cirugía para la prevención del linfedema en mujeres con cáncer de mama y sometidas a la técnica de biopsia del linfonodo centinela para verificar si ocurren o no alteraciones en las actividades de la vida diaria de esas mujeres. Al término del trabajo se resaltó la necesidad de que exista un manual con orientaciones acerca de la biopsia del linfonodo centinela, que sea elaborado y utilizado multidisciplinarmente, y que determine las informaciones más relevantes sobre cada sector de la actuación profesional, especialmente con relación a las prácticas de autocuidado pertinentes a la prevención del linfedema.

Palabras clave: Biopsia del Ganglio Linfático Centinela; Linfedema; Neoplasias de la Mama; Autocuidado; Análisis Cualitativo 